\title{
Photodamage attenuation effect by angelic acid in UVA irradiation-induced damages in normal human dermal fibroblast
}

\author{
Jung-Eun Ku
}

\begin{abstract}
Background: Among various extra stimuli of humans, ultraviolet (UV) has been the most studied factor because it arouses not only internal but also external irritation in the body. UVA, one type of UV rays, has a wavelength between 320 and $400 \mathrm{~nm}$ and capacity to penetrate the skin dermal layer. Therefore, studies on how to reduce UVA-induced maleficence have been investigated vibrantly. Angelic acid has been demonstrated to aid in wound healing and exhibited sedative and psychotropic properties. But there have not been sufficient reports whether angelic acid has potential properties in the cosmeceutical aspect.

Methods: To investigate protective effects of angelic acid on UVA-induced oxidative stress and disruption of extracellular matrix, researchers analyzed cell proliferation rate, intracellular reactive oxygen species (ROS) scavenging capacity, cellular senescence, transcriptional activity of activating protein-1 (AP-1) transcription factor, and gene expression of antioxidant enzymes and connective tissue-related proteins.

Results: Pretreatment of angelic acid in normal human dermal fibroblasts (NHDFs) showed protective effect on UVA-induced proliferative inhibition. Via estimating ROS scavenging activity, angelic acid represented a scavenging effect of excessive increased intracellular ROS which is induced by UVA irradiation. Through quantitative real-time polymerase reaction, antioxidant enzyme and extracellular matrix (ECM)-related protein coded gene expressions were analyzed. Analysis of senescent cell and AP-1 promoter activity by beta-galactosidase assay and luciferase reporter gene assay, respectively, indicated how angelic acid regulates cellular mechanisms associated with connective tissue density.

Conclusions: Through the present study, researchers verify that angelic acid has dermal protective effect against UVA and suggest angelic acid as an efficacious cosmetic material preventing dermal cellular damages.
\end{abstract}

Keywords: Angelic acid, Human dermal fibroblast, Reactive oxygen species, Ultraviolet A, Senescence, Connective tissue

\section{Background}

In human skin, exposure of solar ultraviolet (UV) rays leads to physiological damages, DNA disorder, formation of intracellular reactive oxygen species (ROS), and collapse of connective tissue density via degradation of extracellular matrix (ECM) components (Yel et al., 2014; Bae et al., 2017; Kohl et al., 2011). Three types of UV rays, UVA (315-400 nm), UVB (280-315 nm), and UVC (200-280 nm), compose solar radiation and only UVA

Correspondence: jungeunku@hanmail.net

Department of Cosmetology, Kyung-In Women's University, 63,

Gyeyangsan-ro, Gyeyang-gu, Incheon, Republic of Korea and UVB inflict damage to ground surface because UVC is screened out by the ozone layer (Ko, 2015). The deepest penetration is from UVA; even relative intensity is not more energetic than UVB, which can reach deeper skin layers (Binic et al., 2013; Kim et al., 2016; Song et al., 2016). Increased substantial ROS by UV irradiation in the cells augment proteins that deplete ECM components (Binic et al., 2013; Song et al., 2016; Rittié \& Fisher, 2002; Tsuji et al., 2001).

Cells that are building connective tissue synthesize ECM components which are composed of structural and biochemical proteins to influence cellular function 
reciprocally against diverse cell biology (Hynes, 2009; Lu et al., 2011). Collagen is one of the main extracellular structural components which is responsible for structural integrity and stability with various biological functions like cell growth, differentiation, migration, and even skin aging (Ricard-Blum, 2011; Kim et al., 2017; Jabłońska-Trypuć et al., 2016; Quan et al., 2006). For the importance of structural proteins, especially diverse types of collagen, studies focused on understanding its regulating mechanisms have been pursued.

Angelic acid is a substance found in the essential oil of Anthemis nobilis, a plant from the Asteraceae family, or Angelica from the Apiaceae family, and it exists in an ester form (Ernest, 2006; Craker \& Simon, 1986). It is also isolated from carrots, Euphorbia species and Alkanna tinctoria (Sonobe et al., 1981; Sosath et al., 1988; Papageorgiou, 1978). It has been reported to aid in wound healing in clinical study (Papageorgiou, 1978) and used as sedative and antispasmodic (Ernest, 2006) and psychotropic (Rhind, 2012), but not in skin aspects such as for therapeutic and cosmeceutical use. Thus, the present study is designed to determine the role of angelic acid on UVA-induced oxidative stress and dermal senescence in normal human dermal fibroblasts (NHDFs) by assessing its excessive ROS scavenging capacity and ECM deterioration.

\section{Methods}

\section{Chemicals and reagents}

Angelic acid was purchased from Santa Cruz Biotechnology (Dallas, TX, USA) and was dissolved in dimethyl sulfoxide (DMSO; Sigma Aldrich, St. Louis, MO, USA) to obtain a $1 \mathrm{mM}$ stock solution that was stored at $4{ }^{\circ} \mathrm{C}$ until used. Dulbecco's modified Eagle's medium (DMEM), 1\% penicillin/streptomycin, and TRIzol reagent were purchased from Gibco/Life Technologies (Carlsbad, CA, USA). The 10\% fetal bovine serum (FBS), 3-(4,5-dimethylthiazol-2-yl)-2,5diphenyl-tertazolium bromide (MTT), 2,7-dichlorofluorescin diacetate (DCFH-DA), glutathione (GSH) assay kit, and L-ascorbic acid were purchased from Sigma-Aldrich. The activating protein-1 (AP-1) reporter kit was purchased from BPS Bioscience (San Diego, CA, USA). The miScript II RT kit was purchased from Qiagen (Hilden, Germany) and the Evagreen dye was from Solis BioDyne (Tartu, Estonia). The senescence-associated $\beta$-galactosidase (SA- $\beta$-gal) staining kit was obtained from Biovision (Milpitas, CA, USA), and the manufactured primers for the quantitative real-time polymerase chain reaction (RT-qPCR) analysis were purchased from Macrogen (Seoul, Korea).

\section{Cell culture}

The NHDF derived from human skin cells were obtained from the Lonza Group (Basel, Switzerland) and were maintained in DMEM supplemented with $10 \%$ heat- inactivated FBS, 100 units $/ \mathrm{ml}$ penicillin, and $100 \mu \mathrm{g} / \mathrm{ml}$ streptomycin in a humidified atmosphere of $5 \% \mathrm{CO}_{2}$ at $37{ }^{\circ} \mathrm{C}$. For subculture, the medium was eliminated and cells were rinsed with phosphate-buffered saline (PBS) twice. Then, the cells were detached using trypsin-EDTA and were cultured with fresh complete growth medium in a ratio of 1:5 every $72 \mathrm{~h}$. The reagents such as angelic acid and L-ascorbic acid were diluted with the culture medium before treatment, and final concentrations were adjusted using DMSO.

\section{UVA irradiation}

The cells were plated until they had attained $80-90 \%$ confluence, rinsed with phosphate-buffered saline (PBS), and then were exposed to UVA light in fresh PBS-filled wells without the lid. UVA irradiation was carried out in a closed chamber using UVA lamps (UVP, Upland, CA, USA), and the intensity was detected using a fiberoptic spectrometer system USB2000 (Ocean Optics, Dunedin, FL, USA). After irradiation, the PBS was aspirated from each well and a pre-warmed complete growth medium was immediately added to the wells. The control cells were operated under the same culture conditions except for the UVA exposure.

\section{Cell cytotoxicity}

The cytotoxicity was determined using an MTT assay kit following the manufacturer's protocol. Briefly, the cells were seeded in the culture plate, incubated for $24 \mathrm{~h}$, and then were pretreated for $6 \mathrm{~h}$ with diverse concentrations of angelic acid $(5,10,15$, and $30 \mu \mathrm{M})$ before UVA irradiation. Then, $24 \mathrm{~h}$ after UVA irradiation, the content of each well was changed to a serum-free medium containing $5 \mathrm{mg} / \mathrm{ml} \mathrm{MTT}$ and incubated for $4 \mathrm{~h}$, and then the formazan blue crystals that were formed in the cells after the medium was removed were dissolved with DMSO. The absorbance of the reaction solution was subsequently measured at $540 \mathrm{~nm}$ using an iMark microplate reader (Bio-Rad, Hercules, CA, USA).

\section{DCFH-DA scavenging assay}

The intracellular ROS generation was measured using the fluorescence dye DCFH-DA, which produces a detectable fluorescence when the non-fluorescent DCFH reacts with ROS in cells. The treated cells were incubated with $25 \mu \mathrm{M}$ DCFH-DA at $37{ }^{\circ} \mathrm{C}$ for $1 \mathrm{~h}$, and then the fluorescence intensity was measured using a $\mathrm{BD}$ fluorescence-activated cell sorting calibur (FACSCalibur, flow cytometer, BD Biosciences, San Jose, CA, USA), at excitation and emission wavelengths of 485 and $535 \mathrm{~nm}$, respectively. 


\section{Intercellular GSH content}

GSH content of the cells was measured using the ThiolTracker Violet GSH detection reagent (Invitrogen/Molecular probes, Eugene, OR) according to the manufacturer's protocol. Cells were seeded in six-well plates, incubated overnight, and treated the following day. Subsequent to treatment of angelic acid and UVA exposure for the indicated dose, the cells were washed with PBS once and incubated in PBS containing $10 \mu \mathrm{M}$ (final concentration) ThiolTracker Violet for $30 \mathrm{~min}$ at $37^{\circ} \mathrm{C}$. Then, cells were semiquantified using a FACSCalibur (BD Biosciences).

\section{RNA isolation and qRT-PCR}

The total RNA of each sample was isolated using the TRIzol reagent following the manufacturer's protocol. After the purified RNA had been validated using a spectrophotometer (MaestroNano, Maestrogen, NV, USA), $1 \mu \mathrm{g}$ of the total RNA was used for cDNA synthesis using a miScript II RT kit. The mRNA expression was quantitatively assessed using Evagreen dye with the Line-Gene $\mathrm{K}$ software (BioER, Hangzhou, China), according to the manufacturer's protocol. The primer list for the qRT-PCR is provided in Table 1, and this experiment was performed in triplicate.

\section{SA- $\beta$-gal activity}

The SA- $\beta$-gal staining was carried out according to the manufacturer's instructions, and senescence cell staining was detected $24 \mathrm{~h}$ after UVA irradiation. Briefly, the cells were rinsed twice with PBS, fixed with $0.5 \mathrm{ml}$ fixative solution (4\% formaldehyde and $0.5 \%$ glutaraldehyde in PBS, $\mathrm{pH}$ 7.2) for $20 \mathrm{~min}$, rinsed again with PBS, and then were incubated with the staining solution for $24 \mathrm{~h}$ at $37{ }^{\circ} \mathrm{C}$. Then, the staining solution was removed, and $70 \%$ glycerol was added to each well before the stained cells were examined for senescence using a microscope (Olympus Microscope System IX51, Olympus, Japan).

\section{AP-1 promoter luciferase assay}

For the AP-1 reporter luciferase assays, AP-1 luciferase reporter vectors were transiently transfected with the pSV- $\beta$-galactosidase (pSV- $\beta$-gal) plasmid into the cells. Then, luciferase activity and $\beta$-galactosidase activity were assayed as described previously (Choi et al., 2012). Briefly, after transfection, cells were treated with angelic acid for $6 \mathrm{~h}$ and irradiated with UVA before $24 \mathrm{~h}$ incubation. Then, the cells were re-suspended in Passive Lysis Buffer (Promega Corp., Madison, WI, USA), and the luciferase activity was measured with a Veritas Luminometer (Turnur Designs, Sunnyvale, CA, USA). $\beta$ galactosidase activity was measured using Luminescent $\beta$-galactosidase Detection Kit II (Clontech Laboratories, Inc., Mountain View, CA, USA) according to the manufacturer's protocol. The relative luciferase activity was normalized to $\beta$-galactosidase activity. The results are the averages of three independent experiments.

\section{Statistics}

All the results are presented as the mean percentage \pm standard deviation $(\mathrm{M} \pm \mathrm{SD})$ of three independent experiments. $p$ values $<0.05,0.01$, and 0.001 were considered statistically significant and were determined using Student's $t$ test.

\section{Results}

\section{Pretreatment with angelic acid inhibits UVA-induced cytotoxicity in HDFs}

Prior to estimating protective effect on UVA-induced cytotoxicity, researchers examine whether angelic acid has cytotoxicity as the concentration range is tested. Fibroblast cells were treated with angelic acid $(0-30 \mu \mathrm{M})$ for $24 \mathrm{~h}$, and viability was determined using the MTT assay (Fig. 1a). Then, cells were exposed to $10 \mathrm{~J} / \mathrm{cm}^{2} \mathrm{UVA}$ after $3 \mathrm{~h}$ pretreatment with angelic acid to investigate UVA-induced cytoprotective effect. Cyto-protective effect of angelic acid was also measured using the MTT assay (Fig. 1b). As shown in Fig. 1, angelic acid has no significant cytotoxicity with indicated concentrations. Though there was no significant

Table 1 Overview of qRT-PCR primer sequences

\begin{tabular}{|c|c|c|}
\hline Gene name (symbol) & Forward primer & Reverse primer \\
\hline$\beta$-actin & GGATTCCTATGTGGGCGACGA & CGCTCGGTGAGGATCTTCATG \\
\hline$G P \times 1$ & TTCCCGTGCAACCAGTTTG & GGACGTACTTGAGGGAATTCAGA \\
\hline SOD1 & GGGAGATGGCCCAACTACTG & CCAGTTGACATGCAACCGTT \\
\hline SOD2 & GCCCTGGAACCTCACATCAA & GGTACTTCTCCTCGGTGACGTT \\
\hline CAT & ATGGTCCATGCTCTCAAACC & CAGGTCATCCAATAGGAAGG \\
\hline NRF2 & TACTCCCAGGTTGCCCACA & CATCTACAAACGGGAATGTCTGC \\
\hline $\mathrm{HO}-1$ & GCCTGCTAGCCTGGTTCAAG & AGCGGTGTCTGGGATGAACTA \\
\hline UPA & CCACCAAAATGCT GTGTGCT & GCTTGTCCTTCAGGGCACAT \\
\hline COLIA1 & AGGGCCAAGACGAAGACATC & AGATCACGTCATCGCACAACA \\
\hline MMP1 & TCTGACGTTGATCCCAGAGAGCAG & CAGGGTGACACCAGTGACTGCAC \\
\hline
\end{tabular}



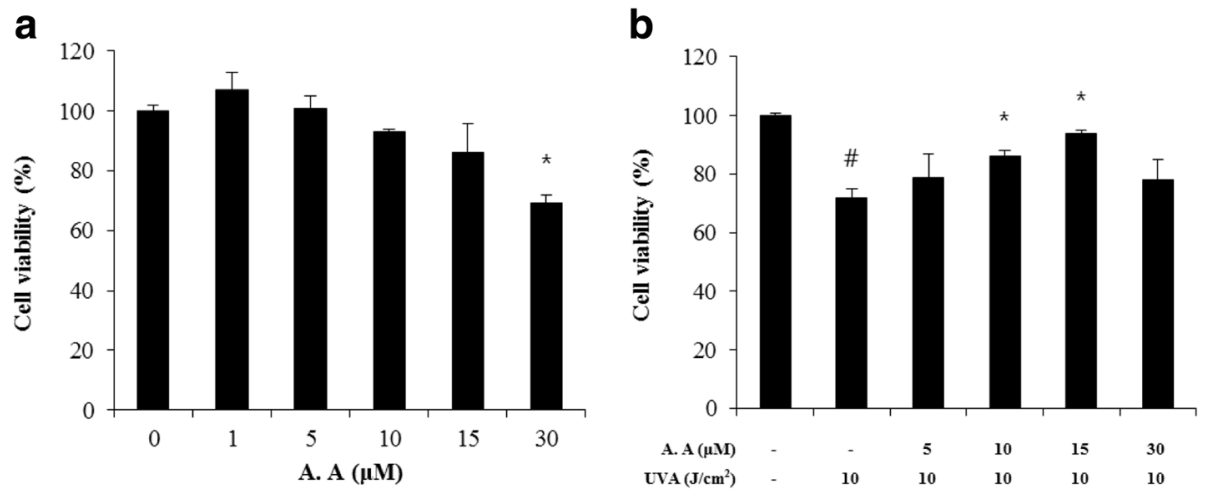

Fig. 1 Determination of NHDF cell viability via MTT assay. a Effect of angelic acid on NHDF cell viability at the indicated concentrations, up to $30 \mu M$. b Protective effect of angelic acid on UVA-induced cellular cytotoxicity in NHDF cells. Cell viability was expressed as a percentage of control and values are $\mathrm{M} \pm \mathrm{SD} ;{ }^{*} p \leq 0.05$ compared with irradiated cells without angelic acid treatment and $\# p \leq 0.05$ compared with negative control cells that were not treated with angelic acid and UVA irradiation

cytotoxicity within $30 \mu \mathrm{M}$ angelic acid, UVA irradiation which reduced cell viability and cells treated with $30 \mu \mathrm{M}$ of angelic acid represented no UVAinduced cytotoxic protective effect. In accordance with these results, researchers investigated diverse effects of angelic acid against UVA irradiation at concentrations up to $15 \mu \mathrm{M}$, in sequence.

\section{Pretreatment with angelic acid reduces UVA-induced intracellular ROS generation in HDFs}

On account of inducing ROS, UVA is regarded as one of major extrinsic factors leading the aging phenomena. Pursuantly, we investigated protective effects of angelic acid on UVA-induced oxidative stress through ROS scavenging efficacy on HDFs, and regulation capacity of GSH and glutathione peroxidase 1 (GPx1) transcriptional expression. As shown in Fig. 2a, cells were pretreated angelic acid before UVA irradiation described reduced DCF fluorescence levels in a dose-dependent manner while UVA-irradiated cells showed increased levels. Furthermore, relative contents of GSH also appeared to have conspicuous antioxidant efficiency, in a dose-dependent manner by angelic acid (Fig. 2b). In the current study, irradiation of UVA reduced the mRNA expression of GPx 1 by 0.68 , compared with their respective control values $(p<0.05$, Fig. $2 \mathrm{c})$. Prior to UVA irradiation, cells were treated with angelic acid at the dose of 5,10 , and $15 \mu \mathrm{M}$ for $6 \mathrm{~h}$ then irradiated with UVA with indicated dosage. Following this treatment, researchers identified the mRNA expression level of GPx1 via qRT-PCR and observed photo-protective effect of angelic acid by increasing GPx1 mRNA expression level as significantly within $15 \mu \mathrm{M}(p<0.05$, except not significant at $5 \mu \mathrm{M}$, Fig. 2c).
Angelic acid activates antioxidant gene expression against UVA irradiation in HDFs

As indicated by the ROS scavenging assay, UVA increased the intracellular ROS levels in HDF cells compared with the non-irradiated cells. Following this treatment, researchers investigated an intrinsic enzyme defense system against UVA-induced oxidative stress, additionally. To evaluate antioxidant gene expression under UVA irradiation, the mRNA expression status of HDF cells were measured using reverse transcriptase PCR and qRT-PCR assay. As presented in Fig. 3, expression levels of superoxide dismutase 1 (SOD1) and 2 (SOD2), catalase $(C A T)$, nuclear factor erythroid 2-related factor 2 (NRF2), and Heme oxygenase 1 (HO1) mRNA were assessed in UVA-irradiated and cotreated with UVA and angelic acid HDFs. Cells were co-treated with angelic acid before UVA radiation, in accordance with the above experiments. Relative mRNA expression of SOD1 and SOD2 revealed that pretreatment with angelic acid stimulated transcriptional levels of SOD1 and SOD2 against UVA-induced ROS generation (Fig. 3a). In detail, the rate of SOD1 mRNA expression was decreased by UVA irradiation while cells which were co-treated with angelic acid and UVA showed increased mRNA levels in a dose-dependent manner by angelic acid $(p<0.05$, not significant in $5 \mu \mathrm{M}$ angelic acid). SOD2 mRNA expression increased as concentration of angelic acid increased to $0.80,0.89$, and 0.97 , respectively. Following UVA irradiation, relative CAT mRNA expression was decreased to 0.53 but angelic acid improved CAT mRNA expression levels against UVA irradiation. In this experiment, CAT mRNA expression was revealed at $0.61,0.78$, and 0.97 compared with the level of the control HDFs (Fig. 3b). NRF2 mRNA expression levels showed as similar in SOD1, SOD2, and CAT. UVA-irradiated cells showed a significantly attenuated 

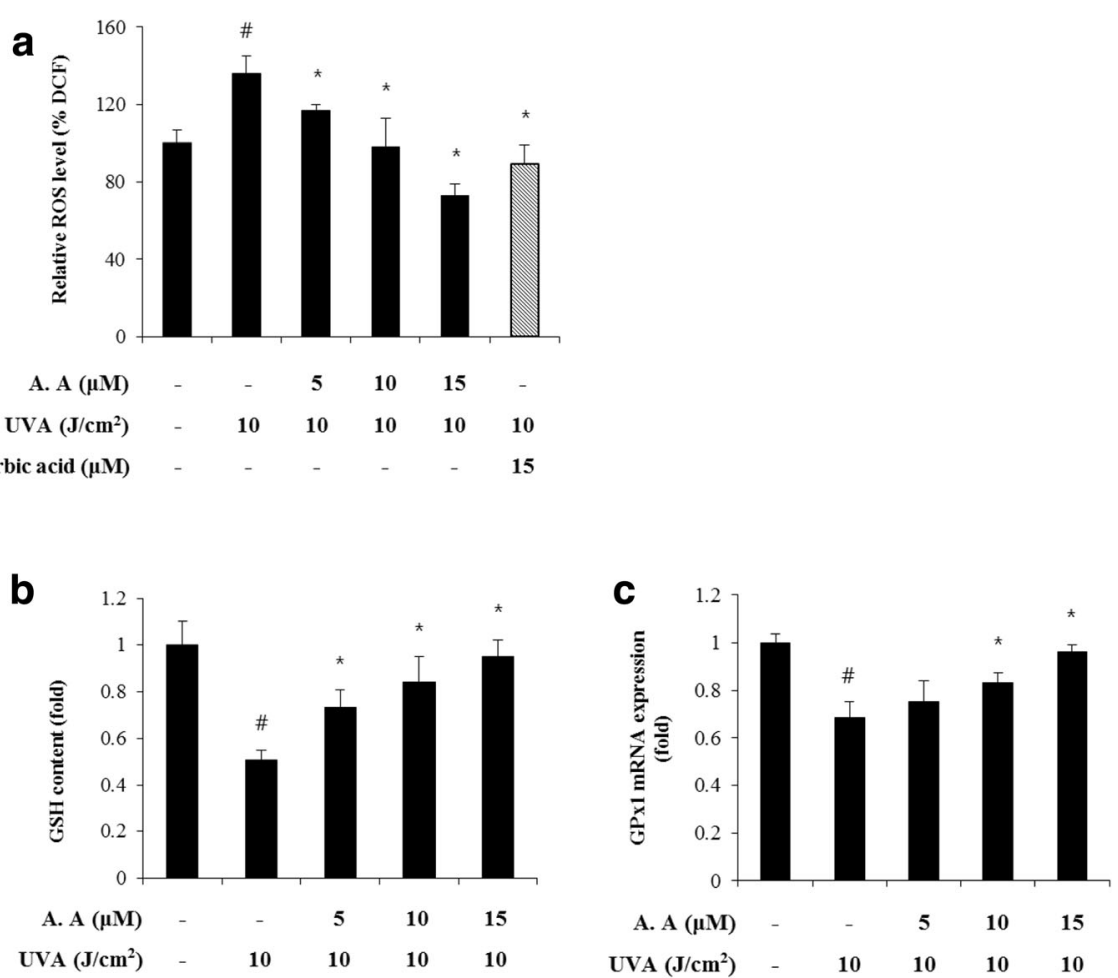

Fig. 2 ROS scavenging capacities of angelic acid and intracellular GSH content estimation. a Effect of angelic acid on DCF fluorescence intensity in NHDF cells. Ascorbic acid was used as positive control, and UVA irradiation $\left(10 \mathrm{~J} / \mathrm{cm}^{2}\right)$ was performed as inducing intracellular ROS in NHDFs. $\mathbf{b}$ Effect of angelic acid on intracellular glutathione contents under UVA irradiation. c Effect of angelic acid on GPx 1 mRNA expression levels against UVA irradiation. Data were expressed as a percentage of control and values are $\mathrm{M} \pm \mathrm{SD}$; ${ }^{*} p \leq 0.05$ compared with irradiated cells without angelic acid treatment and \#p $\leq 0.05$ compared with negative control cells that were not treated with angelic acid and UVA irradiation

expression of NRF2 mRNA compared with the control HDFs. Interestingly, the pretreatment of HDFs with angelic acid significantly showed protective effect against UVA-induced ROS via upregulating NRF2 expression levels (Fig. 3c). Furthermore, $\mathrm{HO}-1$, one of representative NRF2 downstream targets which regulate inflammatory cytokine production and catalyzes the degradation of free heme molecules, also showed increased mRNA expression via angelic acid pretreatment (Fig. 3d).

Pretreatment with angelic acid retards UVA-induced cellular senescence and acid protects UVA-induced extracellular matrix decomposition in HDFs

The above results indicated the protective effects of angelic acid against UVA-induced ROS via scavenging overgenerated intracellular ROS and promoting transcriptional levels of antioxidant enzymes. These consequences led us to examine whether angelic acid regulates cellular senescence which was derived by UVA irradiation in HDF cells. To test this, researchers used a senescence-associated- $\beta$-galactosidase staining kit (BioVision) and HDFs were also operated according to the above procedure. As indicated in Fig. 4a, cells treated with $15 \mu \mathrm{M}$ of angelic acid had no significant difference in cellular senescence. However, $10 \mathrm{~J} / \mathrm{cm}^{2}$ UVA led cellular senescence 11-fold more than control HDFs significantly. The interesting point was that pretreatment of angelic acid reduced UVA-induced cellular senescence by indicated angelic acid concentration gradient. Though $5 \mu \mathrm{M}$ angelic acid-treated cells presented no significantly reduced data, 10 and $15 \mu \mathrm{M}$ angelic acid-treated cells showed remarkable decreased senescent cell population of 34.67 and $21.67 \%$, individually. Following evaluation on cellular senescence, researchers conducted quantitative real-time polymerase chain reaction and luciferase reporter gene activity to investigate alterative mRNA expression of urokinase plasminogen activator $(u P A)$, collagen type I, alpha 1 chain (COL1A1) and matrix metalloproteinase-1 (MMP1), and transcriptional level transition of activator protein 1 (AP-1). To demonstrate whether angelic acid protects ECM from UVA-induced collapse via modulating ECM-associated gene transcriptional level, cells were pretreated angelic acid before UVA irradiation, like the above experiments. After cell harvest and extraction mRNA, synthesis of cDNA also operated through reverse transcription polymerase chain reaction. Then, quantitative polymerase chain reaction was performed to estimate how angelic acid regulates 

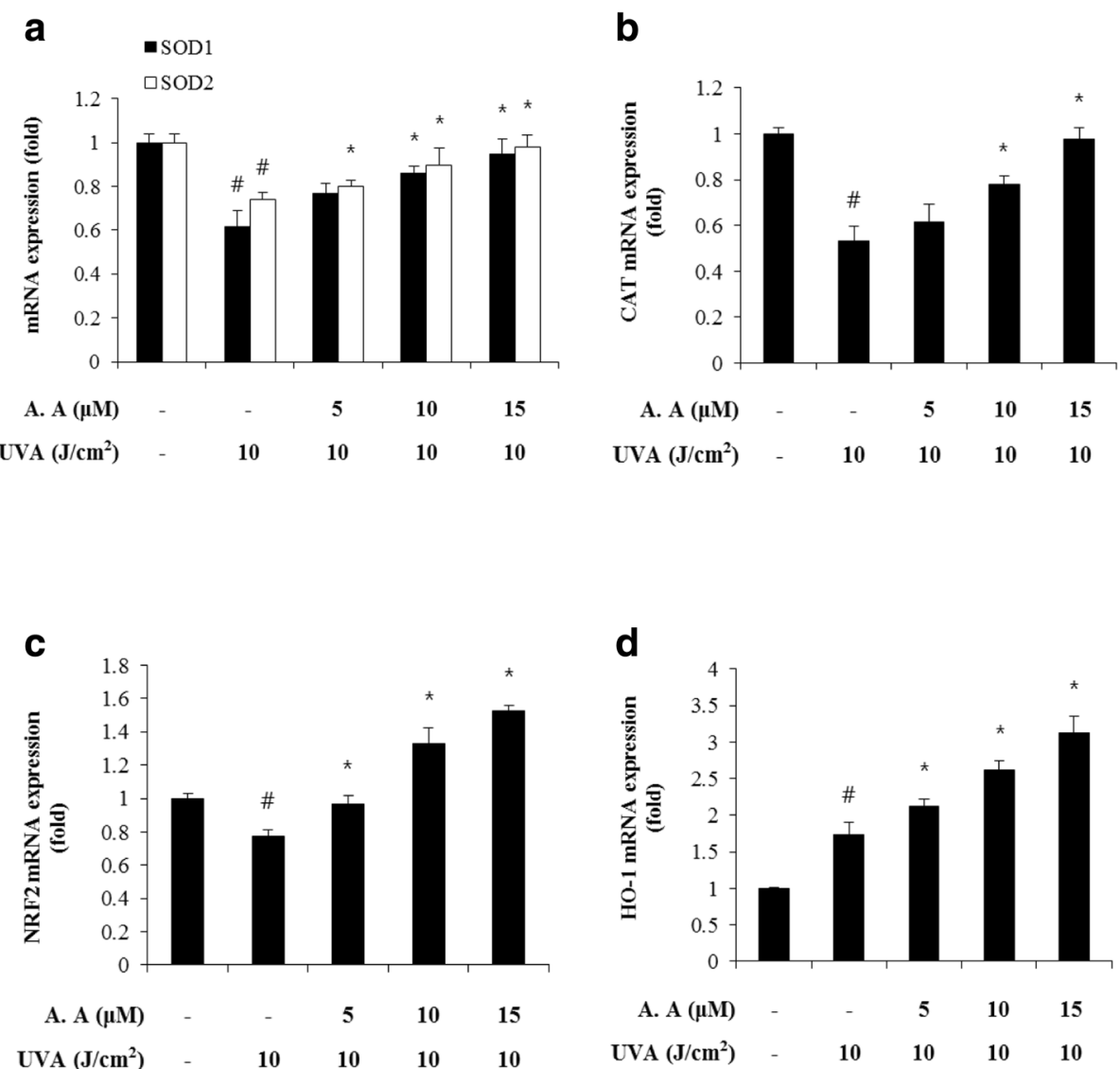

Fig. 3 Analysis of antioxidant gene expression modulating efficacy of angelic acid in NHDF cells. Effect of angelic acid on controlling mRNA expression levels of a SOD1 and SOD2, b CAT, c NRF2, and $\mathbf{d}$ HO-1 in NHDFs, in opposition to UVA. Data were expressed as a percentage of control and values are $\mathrm{M} \pm \mathrm{SD} ;{ }^{*} p \leq 0.05$ compared with irradiated cells without angelic acid treatment and \#p $\leq 0.05$ compared with negative control cells that were not treated with angelic acid and UVA irradiation

gene expression against UVA irradiation in NHDF cells. As shown in Fig. 4b-d, $u P A, C O L 1 A 1$, and $M M P 1$ gene expression levels in NHDFs adduced that pretreatment of angelic acid was efficacious on UVA irradiation which induces breakdown of ECM. Further interesting point is AP-1 promoter luciferase activity. In this experiment, the AP-1 promoter contains luciferase reporter vector which transfected into the NHDF cells. Similar patterns were obtained with ECM regulating gene expression and luciferase activity estimated cells (Fig. 4e). In conclusion, the effect of angelic acid dominates in controlling the transcriptional activity of genes which reconstructs ECM.

\section{Discussion}

ROS generation occurs in respiratory chain from molecular oxygen and mitochondrial metabolism of mammals. But this natural production as a byproduct of homeostasis is important on pathological elimination (Zorov et al., 2014; Murphy, 2009). Exposure to UVA radiation also induces ROS production while it causes oxidative stress and initiates senescence response
(Bickers \& Athar, 2006; Berneburg et al., 2004a; Yin \& Jiang, 2013; Yang et al., 2015), because this stimulus is excessive ROS production. Against stimuli like these, there are enzymatic or non-enzymatic mechanisms that defend against oxidative stress-induced damages by scavenging intracellular ROS levels. In this study, researchers investigate angelic acid to approach as a novel material in therapeutic cosmetic ingredients.

We estimated the cytotoxicity of angelic acid in indicated concentration at first and then demonstrated the protective effect by UVA-induced photo-damages. At 5, 10 , and $15 \mu \mathrm{M}$, angelic acid-pretreated cells showed attenuated cytotoxic damages which influence cell proliferation by $10 \mathrm{~mJ} / \mathrm{cm}^{2}$ of UVA irradiation in HDFs. But in $30 \mu \mathrm{M}$, angelic acid has no significant protective effect, compared with cells only UVA-irradiated.

Subsequently, we demonstrated the intracellular ROS scavenging effect of angelic acid on UVA-induced generation, via analysis of DCF-DA fluorescent intensity, reduced GSH contents, and GPx1 mRNA expression. Pretreatment of angelic acid modulates UVA-induced 

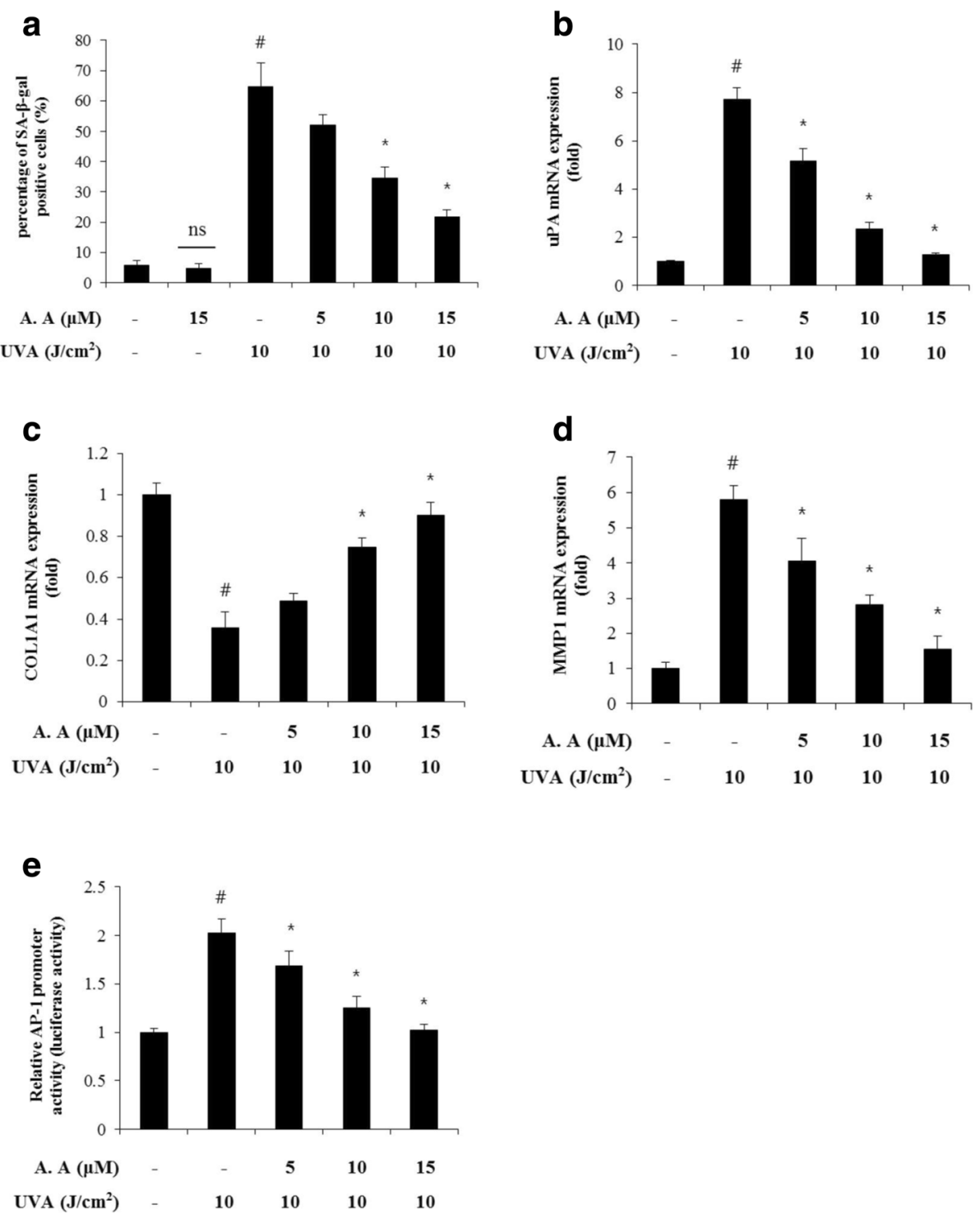

Fig. 4 Protective effect of angelic acid on UVA-induced cellular senescence and ECM controlling gene expression in NHDF cells. a Effect of angelic acid on cellular senescence using SA- $\beta$-gal assay. Effects of angelic acid on gene expression of $\mathbf{b}$ UPA, c COL 1A1, and $\mathbf{d}$ MMP1. e Relative AP-1 promoter luciferase reporter activity using fluorescent intensity. Gene expression of $U P A, C O L 1 A 1$, and MMP1 was evaluated using RT-qPCR with the $2^{-\triangle \triangle C t}$ method and data presented were normalized to $\beta$-actin; ${ }^{*} p \leq 0.05$ compared with irradiated cells without angelic acid treatment and \#p $\leq 0.05$ compared with negative control cells that were not treated with angelic acid and UVA irradiation

ROS levels through activating an internal cellular excessive ROS scavenging mechanism. To research how angelic acid controls other enzymatic defense mechanisms, researchers conducted mRNA expression analysis of SOD1 and SOD2, CAT, NRF2, and HO-1 using qRTPCR. At the test concentration of angelic acid, especially 10 and $15 \mu \mathrm{M}$, above antioxidant enzyme coded gene expressions were significantly increased in dose-dependent manners.

The fibroblasts, one of the major components of the skin, are intimately related with the ECM by synthesizing and secreting matrix macromolecules, such as collagen, elastin, laminin, and fibronectin (Alberts et al., 2002; Khavkin \& Ellis, 2011; Saito et al., 2015). Previous reports have revealed and studied characteristics of the fibroblasts and the relation with various stimuli including intrinsic and extrinsic. Following the precedent study, it has been suggested that UVA and oxidative stress induced by the ray irradiation lead to collapse of ECM via decomposing collagen fibers (Rittié \& Fisher, 2002; Polte \& Tyrrell, 2004; Berneburg et al., 2004b). MMPs, typical enzymes which degrade ECM proteins including collagen and gelatin, are considered responsible as a key regulator in ECM decomposition (Jabłońska- 
Trypuć et al., 2016). Having views on those reports, we aimed at demonstrating whether angelic acid protects UVA-induced ECM decomposition as modulating gene expression which coded ECM proteins, uPA, COL1A1, and MMP1 especially. Further experiments investigated influence on cellular senescence via SA- $\beta$-gal assay and promoter activity of AP-1 which is upstream of the senescence mechanism. As a result, cells treated with angelic acid prior to UVA irradiation showed retardation of UVA-induced cellular senescence and regulated gene expression of ECM proteins, which were intimately related to construction or disruption of connective tissue.

\section{Conclusions}

In conclusion, we verified that angelic acid has photoprotective effect on the HDFs against UVA-induced cytotoxicity, oxidative stress, and cellular senescence. This study elucidates how angelic acid, a new material which has suggestive cosmeceutical applications, militates against UVA-induced damages via revealing unknown cellular mechanisms presented above. Further investigations such as protein level evaluation including in vivo experiments are needed to substantiate biological roles of angelic acid; this study suggests that angelic acid has potential value in the implementation of new therapeutic and cosmetic strategies for skin aging.

\section{Abbreviations \\ A.A: Angelic acid; AP-1: Activating protein-1; CAT: Catalase; COL 1A1: Collagen type I, alpha 1 chain; DCFH-DA: 2,7-Dichlorofluorescin diacetate; \\ DMSO: Dissolved in dimethyl sulfoxide; ECM: Extracellular matrix; FBS: Fetal bovine serum; GPX1: Glutathione peroxidase 1; GSH: Glutathione; HO-1: Heme oxygenase $1 ; \mathrm{M} \pm \mathrm{SD}$ : Mean percentage \pm standard deviation; MMP1: Matrix metalloproteinase-1; MTT: 3-(4,5-Dimethylthiazol-2-yl)-2,5-diphenyl- tertazolium bromide; NHDFs: Normal human dermal fibroblasts; NRF2: Nuclear factor erythroid 2-related factor 2; PBS: Phosphate-buffered saline; pSV- $\beta$-gal: pSV- $\beta$-galactosidase; ROS: Intracellular reactive oxygen species; RT-qPCR: Quantitative real-time polymerase chain reaction; SA- $\beta$ - gal: Senescence-associated $\beta$-galactosidase; SOD1: Superoxide dismutase 1; UPA: Urokinase plasminogen activator; UV: Ultraviolet}

\section{Acknowledgements}

The author thanks all the study subjects and research staff who participated in this work

\section{Funding}

Not applicable.

\section{Availability of data and materials}

Not applicable.

\section{Authors' contributions}

JK performed the experiments, data analysis, and drafted the manuscript.

The author read and approved the final manuscript.

Ethics approval and consent to participate

Not applicable.

\section{Consent for publication}

Not applicable.

\section{Competing interests}

The author declares no competing interests.

\section{Publisher's Note}

Springer Nature remains neutral with regard to jurisdictional claims in published maps and institutional affiliations.

Received: 8 June 2017 Accepted: 19 December 2017

Published online: 20 January 2018

\section{References}

Alberts B, Johnson A, Lewis J, Raff M, Roberts K, Walter P. Molecular biology of the cell. 4th ed. New York: Garland Science; 2002

Bae JS, Han M, Shin HS, Kim MK, Shin CY, Lee DH, et al. Perilla frutescens leaves extract ameliorates ultraviolet radiation-induced extracellular matrix damage in human dermal fibroblasts and hairless mice skin. J Ethnopharmacol. 2017; 195:334-42.

Berneburg M, Plettenberg H, Medve-König K, Pfahlberg A, Gers-Barlag H, Gefeller $\mathrm{O}$, et al. Induction of the photoaging-associated mitochondrial common deletion in vivo in normal human skin. J Invest Dermatol. 2004;122:1277-83.

Bickers DR, Athar M. Oxidative stress in the pathogenesis of skin disease. J Invest Dermatol. 2006;126:2565-75.

Binic I, Lazarevic V, Ljubenovic M, Mojsa J, Sokolovic D. Skin ageing: natural weapons and strategies. Evid Based Complement Alternat Med. 2013;2013:827248.

Choi YM, An S, Lee EM, Kim K, Choi SJ, Kim JS, et al. CYP1A1 is a target of miR892a-mediated post-transcriptional repression. Int J Oncol. 2012;41:331-6.

Craker LE, Simon JE. Herbs, spices, and medicinal plants: recent advances in botany, horticulture, and pharmacology. Binghamton: Haworth Press Inc; 1986.

Ernest S. Culinary herbs. 2nd ed. National Research Council: Canada; 2006.

Hynes RO. The extracellular matrix: not just pretty fibrils. Science. 2009;326:1216-9.

Jabłońska-Trypuć A, Matejczyk M, Rosochacki S. Matrix metalloproteinases (MMPs), the main extracellular matrix (ECM) enzymes in collagen degradation, as a target for anticancer drugs. J Enzyme Inhib Med Chem. 2016;31(Suppl 1):177-83.

Khavkin J, Ellis DA. Aging skin: histology, physiology, and pathology. Facial Plast Surg Clin North Am. 2011;19:229-34.

Kim KS, Han SH, An IS, Ahn KJ. Protective effects of ellagic acid against UVAinduced oxidative stress in human dermal papilla. Asian J Beauty Cosmetol. 2016;14:191-200

Kim MK, Kim EJ, Cheng Y, Shin MH, JH O, Lee DH, et al. Inhibition of DNA methylation in the COL1A2 promoter by anacardic acid prevents UV-induced decrease of type I procollagen expression. J Invest Dermatol. 2017;137:1343-52.

Ko JM. Protective effects of a-mangostin on UVB-induced oxidative stress and cellular senescence. Asian J Beauty Cosmetol. 2015;13:813-8.

Kohl E, Steinbauer J, Landthaler M, Szeimies RM. Skin ageing. J Eur Acad Dermatol Venereol. 2011;25:873-84.

Lu P, Takai K, Weaver VM, Werb Z. Extracellular matrix degradation and remodeling in development and disease. Cold Spring Harb Perspect Biol. 2011; https://doi.org/10.1101/cshperspect.a005058.

Murphy MP. How mitochondria produce reactive oxygen species. Biochem J. 2009;417:1-13.

Papageorgiou VP. Wound healing properties of naphthaquinone pigments from Alkanna Tinctoria. Experientia. 1978;34:1499-501.

Polte T, Tyrrell RM. Involvement of lipid peroxidation and organic peroxides in UVA-induced matrix metalloproteinase-1 expression. Free Radic Biol Med. 2004:36:1566-74

Quan T, He T, Shao Y, Lin L, Kang S, Voorhees JJ, et al. Elevated cysteine-rich 61 mediates aberrant collagen homeostasis in chronologically aged and photoaged human skin. Am J Pathol. 2006;169:482-90.

Rhind JP. Essential oils: a handbook for aromatherapy practice. 2nd ed. London: Singing Dragon; 2012.

Ricard-Blum S. The collagen family. Cold Spring Harb Perspect Biol. 2011; https:// doi.org/10.1101/cshperspect.a004978.

Rittié L, Fisher GJ. UV-light-induced signal cascades and skin aging. Ageing Res Rev. 2002;1:705-20.

Saito Y, Tsuruma K, Ichihara K, Shimazawa M, Hara H. Brazilian green propolis water extract up-regulates the early expression level of $\mathrm{HO}-1$ and accelerates Nrf2 after UVA irradiation. BMC Complement Altern Med. 2015;15:421.

Song E, Chung H, Shim E, Jeong JK, Han BK, Choi HJ, et al. Gastrodia elata Blume extract modulates antioxidant activity and ultraviolet A-irradiated skin aging in human dermal fibroblast cells. J Med Food. 2016;19:1057-64.

Sonobe H, Kamps LR, Mazzola EP, Roach JA. Isolation and identification of a new conjugated carbofuran metabolite in carrots: angelic acid ester of 3hydroxycarbofuran. J Agric Food Chem. 1981;29:1125-9. 
Sosath S, Ott HH, Hecker E. Irritant principles of the spurge family (Euphorbiaceae). XIII. Oligocyclic and macrocyclic diterpene esters from latices of some euphorbia species utilized as source plants of honey. J Nat Prod. 1988:51:1062-74.

Tsuji N, Moriwaki S, Suzuki Y, Takema Y, Imokawa G. The role of elastases secreted by fibroblasts in wrinkle formation: implication through selective inhibition of elastase activity. Photochem Photobiol. 2001;74:283-90.

Yang SR, Park JR, Kang KS. Reactive oxygen species in mesenchymal stem cell aging: implication to lung diseases. Oxidative Med Cell Longev. 2015;2015:486263.

Yel M, Güven T, Türker H. Effects of ultraviolet radiation on the stratum corneum of skin in mole rats. J Radiat Res. 2014;7:506-11.

Yin B, Jiang X. Telomere shortening in cultured human dermal fibroblasts is associated with acute photodamage induced by UVA irradiation. Postepy Dermatol Alergol. 2013:30:13-8.

Zorov DB, Juhaszova M, Sollott SJ. Mitochondrial reactive oxygen species (ROS) and ROS-induced ROS release. Physiol Rev. 2014;94:909-50

\section{Submit your next manuscript to BioMed Central} and we will help you at every step:

- We accept pre-submission inquiries

- Our selector tool helps you to find the most relevant journal

- We provide round the clock customer support

- Convenient online submission

- Thorough peer review

- Inclusion in PubMed and all major indexing services

- Maximum visibility for your research

Submit your manuscript at www.biomedcentral.com/submit 